\title{
Fluctuating Neurologic Symptoms in a Patient With Brain Lesion
}

\author{
Hamid Reza Riasi ${ }^{\mathrm{a}}$, Forod Salehi ${ }^{\mathrm{a}, \mathrm{b}}$, Ali Rajabpour Sanati ${ }^{\mathrm{a}}$
}

\begin{abstract}
There is a broad spectrum of focal brain lesion in humans. They include primary brain tumor, non-neoplastic cysts, metastatic lesion, stroke, vascular malformations, aneurysm, inflammatory lesions and multiple sclerosis. The case was a 45 -year-old female with fluctuating visual problem, ataxia, right upper limbs weakness, and transient amnesia who was referred to the neurologist. She was alert and under treatment from 10 years before by anti-convulsive drug for seizure with unknown etiology. Physical examination revealed ataxic gate, left-sided homonymous lower quadrantanopia and loss of venous pulse in ophthalmoscopy; there were no other pathological findings. Primary brain imaging (axial brain CT scan) was performed which showed a suspected lesion in right-sided parietooccipital area. Brain MRI and CT angiography revealed a heterogeneous lesion in right-sided parietooccipital area without edema and a mass in the form of vascular malformation. Because of the size and location of the lesion, it seemed inoperable. Treatment plan included serial visit and imaging to follow the progress of lesion and probable complications such as intralesional hemorrhage and hydrocephalia.
\end{abstract}

Keywords: Arteriovenous malformation; Brain

\section{Introduction}

Arteriovenous malformations (AVMs) are complicated brain lesions divided into sporadic and familial subgroups with the familial form evident in lower age and similar presentations in both genders [1]. They are without any sex predilection and of a broad spectrum of symptoms and signs [2].

Their prevalence rate is $15-18$ per 100,000 persons [2, $3]$. Its pathologic basis is abnormal where arterial blood enters

Manuscript accepted for publication November 23, 2016

aBirjand Cardiovascular Diseases Research Center, Birjand University of Medical Sciences, Birjand, Iran

${ }^{b}$ Corresponding Author: Forod Salehi, Birjand Cardiovascular Diseases Research Center, Birjand University of Medical Sciences, Birjand, Iran. Email: hamidsalehi500@yahoo.com

doi: https://doi.org/10.14740/jmc2706w venous blood flow without going through capillary bed. Absence of capillary system, which impedes direct arterial blood flow through low-diametric arterials, can lead to significantly increased blood flow and in turn tortuous expansion of the vascular bed [2].

Physiopathologic process during AVM evolution generally ends in hemodynamic disturbance in a part of brain beside overflow in AVM bed, causing steal of blood from normal part of brain. Hence, AVM not only is revealed in imaging but also affects normal brain tissue [4].

These lesions (AVM) generally are non-hereditary but their pathologic process begins in the fetal period. The affected baby with the congenital lesion is normal and may have no symptoms until only after years because of the tininess of the lesion [5].

Symptoms and signs are secondary to mass effect and hemodynamic disturbance, while edema and hemodynamic disturbance depend on the location, growth rate and related complication of AVM (e.g., hemorrhage, etc.) [6].

The most serious complication of AVM, which causes a clinical disaster, is intracranial hemorrhage secondary to vascular bed rupture $[2,6]$.

Brain cortex mechanical or hemodynamic disturbance causes seizure because of pathologic discharges of a series of affected neurons [6].

\section{Case Report}

The patient was a 45-year-old female epileptic case who was under treatment since 10 years ago with unknown etiology. This time, she was referred to neurologic department by a series of symptoms which had begun since last month including ataxia, forgetfulness, and fluctuating visual problems. She was alert and under treatment by antiepileptic drug (carbamazepine) for seizure with unknown etiology.

Physical examination revealed ataxic gate wide base gate, left-sided homonymous lower quadrantanopia, and loss of venous pulse in ophthalmoscopy.

Laboratory data including CBC, electrolytes, blood sugar, kidney and liver function tests, and electrocardiography were normal.

Axial brain CT scan was performed: a suspected lesion size of $(22 \times 24 \mathrm{~mm})$ in right-sided parietooccipital area was seen (Fig. 1). Brain MRI and CT angiography revealed a heterogeneous lesion size of $(22 \times 26 \mathrm{~mm})$ with serpentine appear- 

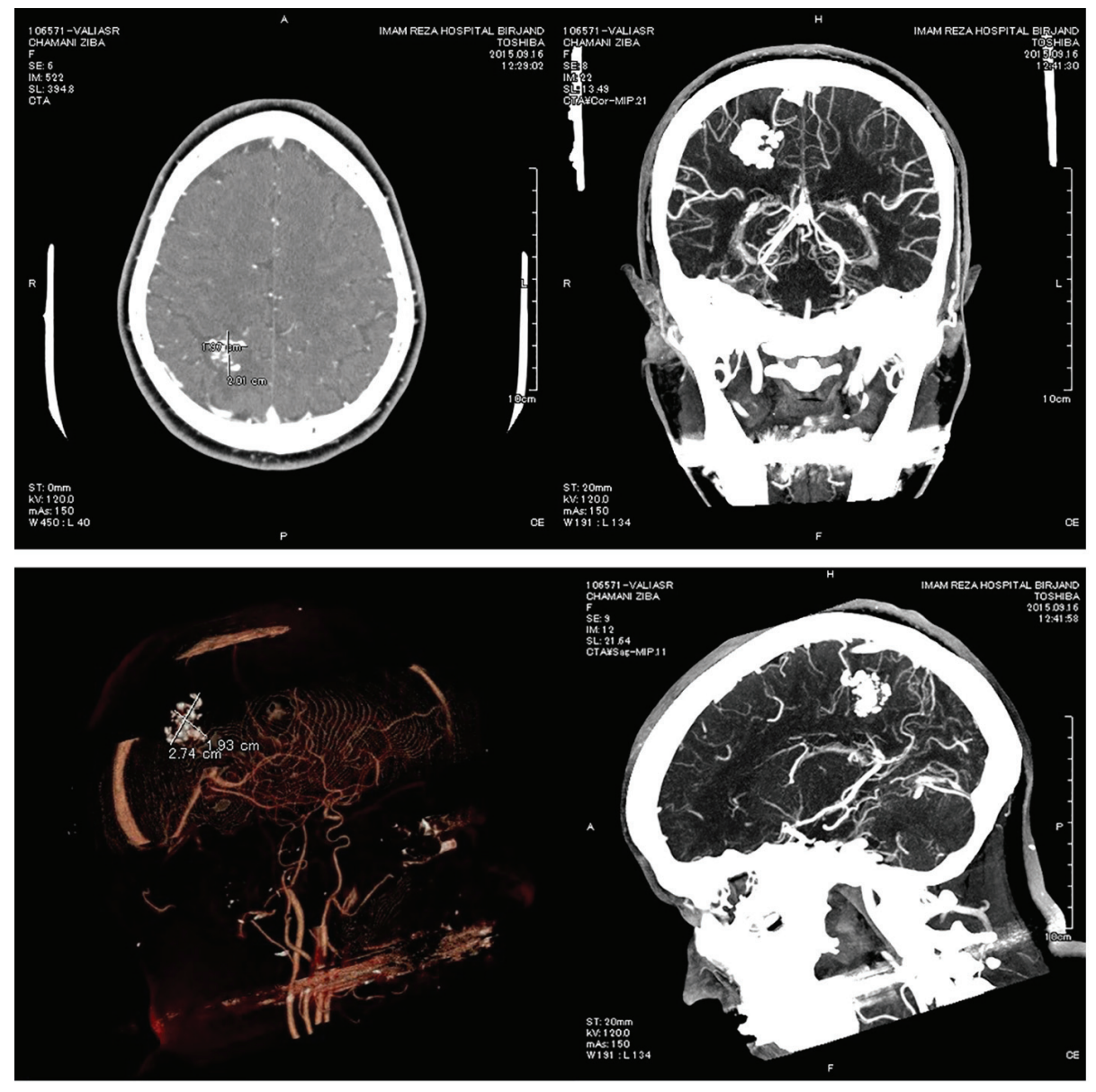

Figure 1. Axial brain CT angiography.

ance in right-sided parietooccipital area without objective sign of edema and mass effect in favor of vascular malformation. MRA and MRV imaging was normal. The patient underwent antiepileptic drug.

All symptoms subsided and the patient was discharged with closed follow-up. Three times of CT angiography during 6 months revealed no enlargement of lesion, and there was no recurrence of symptoms.

\section{Discussion}

This abnormality usually becomes symptomatic at young age and middle age, although it has also been found symptomatic at both extremes of 5 - 50 years age range $[2,7]$.

The most frequent symptom and sign on admission is symptom secondary to hemorrhage, headache, seizure and focal neurologic sign $[2,6]$. Because of the nature of lesion, all symptoms have fluctuation [7]. This case was in older age with misleading symptoms dissimilar to classic ones, e.g., defective visual field and fluctuating ataxia. New onset seizures in adulthood should not be overlooked because there may be usually an important lesion in the brain as its etiology especially vascular malformation $[6,8]$. Selective imaging in this lesion includes brain MRI and CT angiography [1, 9]. In clinical practice, it must be mentioned that in solid occupying lesions (SOLs), lumbar puncture is contraindicated because of the danger of brain herniation.

\section{Treatment}

There is a broad spectrum of recommended managements including microsurgery [10], radiosurgery with Gama knife (GKS) [11], and neurointerventional method (coil and embolization) [12]. Combined treatment, GKS with coil or embolization, can reduce mass lesion and reduce the size of AVM and result in a better outcome in patient management [13].

It is important that the interventional method for cavernous AVM be usually done through venous access.

\section{Conclusion}

In the referred patient, central nervous system (CNS) vascular malformation is highly probable because of neurologic problems especially fluctuating focal neurologic symptoms (seizure, focal paresis, visual field defect and cerebellar sign), 
CNS steal syndrome and chronic headache syndromes whose headache rhythm and period have changed recently. It is important to know that primary imaging for these patients may not clearly define the lesion or be falsely negative. Therefore, we advise MRI/MRA/MRV, CT angiography and even conventional angiography in these situations.

Treatment plan for these lesions is based on location, distribution of vascular malformation, age, accompanying lesion and malformation progress in serial imaging.

\section{Acknowledgments}

The authors thank Dr. Roozegary for editing the manuscript.

\section{Conflicts of Interest}

None.

\section{References}

1. am Heine I About AVMs

2. van Beijnum J, van der Worp HB, Schippers HM, van Nieuwenhuizen O, Kappelle LJ, Rinkel GJ, Berkelbach van der Sprenkel JW, et al. Familial occurrence of brain arteriovenous malformations: a systematic review. J Neurol Neurosurg Psychiatry. 2007;78(11):1213-1217.

3. Al-Shahi R, Warlow C. A systematic review of the frequency and prognosis of arteriovenous malformations of the brain in adults. Brain. 2001;124(Pt 10):1900-1926.

4. Markl M, Wu C, Hurley MC, Ansari SA, Carroll TJ, Rahme RJ, Aoun SG, et al. Cerebral arteriovenous mal- formation: complex 3D hemodynamics and 3D blood flow alterations during staged embolization. J Magn Reson Imaging. 2013;38(4):946-950.

5. van Beijnum J, van der Worp HB, Algra A, Vandertop WP, van den Berg R, Brouwer PA, van der Sprenkel JW, et al. Prevalence of brain arteriovenous malformations in first-degree relatives of patients with a brain arteriovenous malformation. Stroke. 2014;45(11):3231-3235.

6. Whapham JM. Intracranial AVM: Endovascular Management and Treatment. Endovascular Interventions. Springer. 2014:39-60.

7. Luo J, Lv X, Jiang C, Wu Z. Brain AVM characteristics and age. Eur J Radiol. 2012;81(4):780-783.

8. Sibia RS, Kumar A, Sharma H. Seizure in later life: an ode to the elderly. International Journal. 2014;2(4):1393.

9. Unlu E, Temizoz O, Albayram S, Genchellac H, Hamamcioglu MK, Kurt I, Demir MK. Contrast-enhanced MR 3D angiography in the assessment of brain AVMs. Eur J Radiol. 2006;60(3):367-378.

10. Starke RM, Komotar RJ, Hwang BY, Fischer LE, Garrett MC, Otten ML, Connolly ES. Treatment guidelines for cerebral arteriovenous malformation microsurgery. Br J Neurosurg. 2009;23(4):376-386.

11. Flickinger JC, Kondziolka D, Maitz AH, Lunsford LD. Analysis of neurological sequelae from radiosurgery of arteriovenous malformations: how location affects outcome. Int J Radiat Oncol Biol Phys. 1998;40(2):273-278.

12. Huded V. Endovascular balloon-assisted glue embolization of intranidal high flow fistula in brain AVM. J Neurosci Rural Pract. 2013;4(Suppl 1):S148-149.

13. Ha JK, Choi SK, Kim TS, Rhee BA, Lim YJ. Multi-modality treatment for intracranial arteriovenous malformation associated with arterial aneurysm. J Korean Neurosurg Soc. 2009;46(2):116-122. 